\title{
COMMENTARY
}

\section{Domestic migrant workers in India returning to their homes: emerging socioeconomic and health challenges during the COVID-19 pandemic}

\section{AUTHORS}

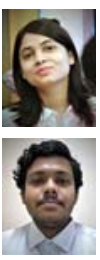

Sweety Suman Jha ${ }^{1}$ MBBS, Junior Resident

\section{CORRESPONDENCE}

*Dr Arista Lahiri alpublications2016@gmail.com

\section{AFFILIATIONS}

${ }^{1}$ Department of Preventive and Social Medicine, All India Institute of Hygiene and Public Health, 110, C.R. Avenue, Kolkata 700073, India

2 Department of Community Medicine, College of Medicine \& Sagore Dutta Hospital, 578 B. T. Road, Kamarhati, Kolkata 700058, India

\section{PUBLISHED}

20 November 2020 Volume 20 Issue 4

\section{HISTORY}

RECEIVED: 11 June 2020

REVISED: 21 August 2020

ACCEPTED: 8 October 2020

\section{CITATION}

Jha SS, Lahiri A. Domestic migrant workers in India returning to their homes: emerging socioeconomic and health challenges during the COVID-19 pandemic. Rural and Remote Health 2020; 20: 6186. https://doi.org/10.22605/RRH6186

\section{ETHICS APPROVAL}

The current article is a commentary on the national scenario regarding the migrant workers who are returning back home after a stretched Lock-down. This article do not take into account any individual level data from any individual. This is not a research article comprising of first-hand or secondary data collection. This article infers on the available published evidences. It was not considered necessary for approval by Institutional Ethics Committee.

This work is licensed under a Creative Commons Attribution 4.0 International Licence

\section{ABSTRACT:}

Domestic migrant workers were stranded far from home when India declared nationwide lockdown to combat the pandemic of novel coronavirus (COVID-19). A large number of these workers were left with no economic support, no food and in many cases nowhere to live. The pandemic posed a serious health threat to these people, and the socioeconomic insecurity pushed them towards the edge of sustainability. Many of the migrants began walking home and accepted an uncertain fate if they could not return back home. The Government of India initiated efforts to provide transport support with special train services from the 
beginning of May 2020. While the migrants have started to return to their villages and towns, the states are facing the challenges of preventing the spread of COVID-19. The point-of-entry screening, quarantine and isolation facilities have increased substantially in capacity, although the quality of care remains a point of concern.
Back at their homes, the migrants are enduring stigma, discrimination and poor social security. In order to avert the brewing humanitarian crisis, empathetic administration combined with political will is a must. Prudent, evidence-based decisionmaking in the economic and health sectors is also necessary.

\section{Keywords:}

COVID, domestic, India, migrant workers, social determinants of health, socioeconomic.

\section{FULL ARTICLE:}

\section{Background}

Migrants, typically in low- and middle-income countries, are those who mostly move from villages to work in larger urban sectors as domestic helpers, drivers and gardeners, or as daily-wagers on construction sites, building malls, flyovers and homes, or as street vendors. The UN's Migration Agency considers any person who is moving or has moved across an international border or within a state away from his/her place of origin, regardless of the cause or description of the indented activities, as a migrant ${ }^{1}$. Currently, international migrants constitute $3.5 \%$ of the global population, compared to $2.8 \%$ in the year 2000. In 2019, regionally, Europe hosted the largest number of international migrants ( 82 million), followed by North America (59 million), and North Africa and West Asia (49 million) ${ }^{2}$. In India, about 5.1 million migrated from outside of the country, constituting $1.6 \%$ of the migrants in India 3 .

Migration in recent times is the outcome of delicate interactions of pre-existing socioeconomic and political situations, sometimes complicated by humanitarian crises and disasters ${ }^{4}$. In this context, the distinction between migrants and refugees needs special mention because the latter are mostly persons fleeing armed conflict or persecution and cannot safely return home. Migrants choose to move in search of a better quality of life either temporary or permanent, usually with the perceived protection of government ${ }^{\mathbf{5}}$. As a key component of population dynamics, migration often has a significant part in public health challenges, sometimes becoming a challenge in itself. Migrants are considered at higher risk for a range of health problems, be it a novel contagion or the usual cough or cold. Poverty is the chief determinant in this case, while restricted access to health care for undocumented migrants plays a part in some countries ${ }^{6}$.

\section{Migrant workers and lockdowns}

The novel coronavirus (COVID-19) pandemic and the resulting travel restrictions, lockdown and panic trapped a large number of migrant workers from Cambodia, Myanmar and other countries in Thailand, where they had been working in local industries and in tourism. In the Gulf countries, millions of migrants from India, Bangladesh, Nepal and Pakistan were in forced lockdown, without wages and under threat of deportation ${ }^{\mathbf{7}}$. In response to the pandemic, India enforced the world's largest lockdown from 25 March 2020 putting ban on all sorts of travel, and the livelihoods of a large proportion of the domestic migrants were affected. In India, more than 260 million people are thought to be domestic migrant workers as per the last census ${ }^{3}$. Journalists have reported that, after the sudden announcement, 50 000-60 000 people had to relocate to their rural areas of origin in only a few days ${ }^{8}$. Reports suggest that, by 31 March, 21604 camps were put up to provide accommodation, food and other basic needs of 66000 migrant workers $^{9}$. These early reports clearly indicate difficulties with infrastructure accessibility on the part of the stakeholders despite the best efforts from the Ministry of Home Affairs.

Difference in employer perceptions of the problem of these migrant laborers and execution of mitigation plans are important factors leading to the current situation. As a result of the interplay of several sociopolitical factors, about $42 \%$ of people in these disadvantaged groups were left with no ration, while up to $33 \%$ were stuck in cities without access to food, safe water and money ${ }^{9}$. Forced deprivation of jobs and earnings, coupled with restrictions on movement associated with lockdown, puts these people and their families to the brink of survival, including an immediate effect on food intake and the health outcomes of children. Health risks are magnified by the intrinsic vulnerability of the migrants during travel, for example in cases of pregnant women, children, infants and people with disabilities ${ }^{\mathbf{1 0}}$.

\section{Discrimination and psychological condition of returning migrants}

The relationship between health and migration is dynamic and complex, mediated and moderated through socioeconomic determinants (eg job, income, education and housing) and social security ${ }^{\mathbf{1 0}}$. COVID-19 has a psychological impact, as many of the stranded migrant workers are gravely concern about their families at home, and distressed by the sudden onset financial crisis ${ }^{\mathbf{1 1}}$. The anxiety and fear cause unrest and a dire need to return home despite the adversities brought about by the epidemic and the measures to control it. In April, thousands of migrant labourers and their families walked barefoot to get home. So far, more than a dozen migrant laborers have been reported to have lost their lives on this venture ${ }^{\mathbf{1 2}}$. On returning to their villages or home towns, it is difficult for the migrants to find work and start earning money. Migrant workers returning home are battling stigma and discrimination in their villages. The families, irrespective of their travel status, are more often harassed, discriminated and singled out. In some villages, they face ostracisation, even after completing the mandatory 14 -day quarantine period ${ }^{\mathbf{1 3}}$.

Migrants are stigmatised and unjustly discriminated against for spreading disease, and such attitudes further risk wider public 
health outcomes, including for host populations, since the migrants could be fearful to seek treatment or disclose symptoms ${ }^{\mathbf{1 4}}$. A shortage of means of prevention such as masks, handwash and sanitiser will lead to more acquisition of infection and to the spread of the disease in communities. As the migrants return, there can also be the issue of overcrowding and lack of physical distancing in their communities and residences, which poses a great threat - especially to older people.

\section{Social crisis of the COVID pandemic and its impact on health}

The returning migrants see their home in the village as ensuring food and the comfort of their families ${ }^{15}$. However, at home, these people are faced with many social and health challenges. As a result, the lockdown is turning into a humanitarian crisis. The limited access of people to necessary medical care, overcrowding, poor hygiene and scarcity of food increases community transmission of the virus. Migrant workers returning home could become vectors, carrying COVID-19 to unaffected states and villages, and these areas are likely to have spike of COVID-19 cases. Reportedly, during a period in June, $56 \%$ of the caseload in West Bengal was attributed to the migrant returnees, with a growing burden in rural cases, and a $10 \%$ positivity proportion among them ${ }^{\mathbf{1 6}, \mathbf{1 7}}$. In May, 70\% of new cases in Uttar Pradesh were attributed to migrant workers ${ }^{\mathbf{1 8}}$. A temporal trend and the established epidemiological links connect these everdisadvantaged migrants to the growth of this pandemic. The protection of the physical health of migrants alongside their psychological health is thus an important aspect, especially with the current perspective of the pandemic, because it will help both the disadvantaged migrant population and the society as a whole.

Lack of both social security and of infrastructure play a deeper role in this brewing crisis. Many migrants are often excluded from various benefits under national health programs. As a result, in the current situation of community spread of COVID-19, early detection, testing, diagnosis, contact tracing and care seeking has become difficult, if at all accessible, among migrants - thus increasing the risk of outbreaks in these populations, and that symptoms may go unchecked or even actively concealed, which adds the threat to health of communities. Rural people remain dependent mostly on the public healthcare system with resource mobilisation from the urban sector. The return of migrants to rural areas will put the infrastructure in double jeopardy, first by increases in infection and second a supply problem brought about by the lockdown and its economic impact.

\section{The way forward}

The Sustainable Development Goals emphasise smooth and responsible migration and mobility of people, by virtue of preplanned and scientifically designed migration policies ${ }^{\mathbf{1}}$. Domestic migrants, who comprise a major part of the urban poor, do not enjoy the benefits of such a well-planned strategy. With the lockdown being imposed and widespread restrictions on mobility, migrants have been left with no social security whatsoever, despite the legislative supports offered by the national government. While about 10000 Indian rupees a month would just be enough for sustenance for a family of migrants, micro, small and medium enterprises were left with no other choice but to curb their aid in view of the continued lockdown ${ }^{\mathbf{1 9 , 2 0}}$. Migrants walking thousands of kilometres is of great concern, and it is the responsibility of the system overall to facilitate their transportation. Arrangement of vehicles, in-transit shelters and point-of entry screening are the three most important responsibilities in this situation. Although the decision was not made promptly, the Government of India announced special trains on 2 May for the migrants to return to their homes ${ }^{\mathbf{2 1}}$. The government assured a relief amount of 10 billion rupees for the migrants, along with free food grains (an additional 35 billion rupees) ${ }^{\mathbf{2 2}}$. Despite the huge spending, the demands remain largely unmet. Instead of allotment of financial relief packages to micro, small and medium enterprises on a later date, economic support for these employers at an early date as legislation and as a social responsibility would have made a reasonable difference.

Migrants staying in temporary settlements or camps due to either undergoing quarantine or stopping on their way back home have often complained of overcrowding and poor facilities, no food and poor sanitary conditions, and many of them fled ${ }^{\mathbf{2 3}}$. In anticipation of heavy influxes to the communities, individual states initiated mass testing and increased capacities of quarantine facilities specifically for the returning migrants. However, the sheer numbers may exceed the capacity of the system. The strategy of home isolation of the infected individuals where possible is a welcome change, and it depressurises the health system infrastructure efficiently. Presumably, those of higher socioeconomic status have the provisions to isolate infected individuals at home until remission. This will allow room for those who live in poor sanitary and environmental conditions, such as migrants, to get facility-based care. However, the quality of care remains a point of concern.

Incentive-based active community surveillance will act as a second opportunity for screening of migrants. Health education, and successfully addressing fear and panic by proper demonstration of protective practices during community-surveillance activities, may be a strategy for inducing and sustaining behaviour change of communities. Professional help from clinical psychologists may be of great relevance at point of entry and at isolation/quarantine facilities. While the lockdown is creating a humanitarian crisis, a feasible way out may be building protective behaviour among community members. Communities managing the influx of migrant workers need to be specially managed to avoid stigma and discrimination, and encouraged to be forthcoming in reporting any symptoms during active surveillance. The village and community leaders, in collaboration with frontline health workers, should come forward in this regard.

There is no doubt that the pandemic will be followed by an economic crisis, which ultimately will lead to a decline in people's living standards, reduced employment opportunities, and social instability. Therefore, instead of stigmatisation and discrimination, social inclusion and social support should be a strategy in the midst of this crisis. Local employment should be considered as a strategy to combat the economic crisis by handling it as small 
market sectors. Associated with any such crisis is an overt disturbance in law and order. Empathetic administration, political will and social motivation coupled with determination and technical expertise of the healthcare workers only can aid the nation in this hour of need. All means to take care to the doorstep of those at the lower end of the equity spectrum should be used to handle this developing crisis.

\section{REFERENCES:}

1 United Nations. Migration. 2018. Available: web link (Accessed 26 May 2020).

2 United Nations Department of Economic and Social Affairs. The number of international migrants reaches 272 million, continuing an upward trend in all world regions, says UN. 2019. Available: web link (Accessed 26 May 2020).

3 Ministry of Home Affairs. Census of India: Migration. Available: web link (Accessed 26 May 2020).

4 World Health Organization. Health and foreign policy: influences of migration and population mobility. Available: web link (Accessed 26 May 2020).

5 United Nations High Commissioner for Refugees. UNHCR viewpoint: 'Refugee' or 'migrant' - which is right? Available: web link (Accessed 26 May 2020).

6 Vignier N, Bouchaud O. Travel, migration and emerging infectious diseases. Journal of the International Federation of Clinical Chemistry and Laboratory Medicine 2018; 29(3): 175-179.

7 Ivakhnyuk I. Coronavirus pandemic challenges migrants worldwide and in Russia. Population and Economics 2020; 4(2): 49-55. DOI link

8 Press Trust of India. Lockdown in India has impacted 40 million internal migrants: World Bank. 2020. Available: web link (Accessed 28 May 2020).

9 Bhagat RB, Reshmi RS, Harihar S, Archana KR, Dipti G. The COVID-19, migration and livelihood in India: challenges and policy issues. Migration Letters 2020; 17(5). DOI link

10 Marceca M. Migration and health from a public health perspective. People's movements in the 21st century - risks, challenges and benefits. 2017. Available: web link, DOI link (Accessed 27 May 2020).
11 Press Trust of India. Migrant workers need social protection to overcome trauma in lockdown: Health Ministry. Available: web link (Accessed 27 May 2020).

12 Abi-Habib M, Yasir S. India's coronavirus lockdown leaves vast numbers stranded and hungry. 2020. Available: web link (Accessed 27 May 2020).

13 Hindustan Times. Migrant workers battle stigma, bias back home. 2020. Available: web link (Accessed 27 May 2020).

14 Kluge HHP, Jakab Z, Bartovic J, D'Anna V, Severoni S. Refugee and migrant health in the COVID-19 response. The Lancet 2020; 395(10232): 1237-1239. DOI link

15 Biswas S. India's pandemic lockdown turns into a human tragedy. 2020. Available: web link (Accessed 27 May 2020).

16 Moneycontrol. Coronavirus pandemic. 56\% COVID-19 cases in West Bengal are migrant workers. 2020. Available: web link (Accessed 20 August 2020).

17 WB Health. Welcome to WB Health portal. Available: web link (Accessed 20 August 2020).

18 Times of India. Covid-19: Migrants account for 70\% of new UP cases. 2020. Available: web link (Accessed 20 August 2020).

19 The Financial Express. An NPS would have stopped migrant exodus. 2020. Available: web link (Accessed 21 August 2020).

20 CEIC Data. India: economic indicators, historic data and forecasts. Available: web link (Accessed 21 August 2020).

21 Ministry of Railways. Movement of stranded persons by Shramik Special Trains. 2020. Available: web link (Accessed 28 May 2020).

22 PM CARES Fund. PM's Citizen Assistance \& Relief in Emergency Situations Fund. Available: web link (Accessed 21 August 2020).

23 Biswas S. India migrants running away from quarantine camps. 2020. (Accessed 27 May 2020).

This PDF has been produced for your convenience. Always refer to the live site https://www.rrh.org.au/journal/article/6186 for the Version of Record. 